\title{
Activity Monitor
}

National Cancer Institute

\section{Source}

National Cancer Institute. Activity Monitor. NCI Thesaurus. Code C156897.

A consumer, wearable device that is designed to collect and display information about an individual's activities. Information collected may include steps, stairs climbed, distance traveled, calories used, heart rate, sleep quality, or other metrics. 